\title{
Evidence for Stable High-Temperature Ferromagnetism in Fluorine-Treated $\mathrm{C}_{60}$
}

\author{
Rajen Patel ${ }^{1}$ and Frank J. Owens ${ }^{2}$ \\ ${ }^{1}$ Armament Research, Development and Engineering Center, Picatinny, NJ 07806, USA \\ ${ }^{2}$ Department of Physics, Hunter College and Graduate Center, City University of New York, \\ 696 Park Avenue, New York, NY 10065, USA
}

Correspondence should be addressed to Frank J. Owens; owensfj@gmail.com

Received 13 November 2012; Accepted 2 January 2012

Academic Editor: Zhongfang Chen

Copyright (C) 2013 R. Patel and F. J. Owens. This is an open access article distributed under the Creative Commons Attribution License, which permits unrestricted use, distribution, and reproduction in any medium, provided the original work is properly cited.

It is shown by magnetic field dependent ac susceptibility, magnetic force microscopy, and ferromagnetic resonance that exposure of $\mathrm{C}_{60}$ to fluorine at $160^{\circ} \mathrm{C}$ produces a stable ferromagnetic material with a Curie temperature well above room temperature. The exposure to fluorine is accomplished by decomposing a fluorine-rich polymer, trifluorochloroethylene $\left[\mathrm{F}_{2} \mathrm{C}-\mathrm{CFCl}\right]_{n}$, which has $\mathrm{C}_{60}$ imbedded in it. Based on previous experimental observations and molecular orbital calculations, it is suggested that the ferromagnetism is arising from crystals of $\mathrm{C}_{60}-\mathrm{F}$.

\section{Introduction}

There has been much interest in the material science community in synthesizing molecular-based ferromagnetic materials because of the potential to chemically engineer their properties and the possible ease of production. The $\mathrm{C}_{60}$ molecule has played an important role in this possibility because of a number of reports of ferromagnetism in it. In 1991 a complex of $\mathrm{C}_{60}$ and the strong electron donor molecule $\mathrm{C}_{2} \mathrm{~N}_{4}\left(\mathrm{CH}_{3}\right)_{8}$ (TDAE) were found to be ferromagnetic at $16.1 \mathrm{~K}$ [1]. Subsequently ferromagnetism having a Curie temperature of $500 \mathrm{~K}$ was reported in a two-dimensional polymeric form of $\mathrm{C}_{60}$ produced by high pressure $(6 \mathrm{GPa})$ and high temperature in the vicinity of $1000 \mathrm{~K}$ [2-4]. It is known that $\mathrm{C}_{60}$ when subjected to UV light forms oligomers most of which are dimers [5]. It has been reported that when the photolysis is done in the presence of oxygen the material is ferromagnetic well above room temperature $[6,7]$. There are a number of reports of ferromagnetism in halogenated $\mathrm{C}_{60}$. $\mathrm{C}_{60}$ subjected to a heat treatment in the presence of iodine is shown to be ferromagnetic having a Curie temperature of $60 \mathrm{~K}[8,9]$. Doping with a mix of iodine and bromine produced a material which was ferromagnetic below $30 \mathrm{~K}$ $[10,11]$.
In this work it is shown by magnetic field dependent $\mathrm{AC}$ susceptibility, magnetic force microscopy, and ferromagnetic resonance that $\mathrm{C}_{60}$ treated with fluorine is ferromagnetic well above room temperature. The $\mathrm{C}_{60}$ was exposed to fluorine by embedding it in a fluorine-rich polymer, polytrifluorochloroethylene, $\left[\mathrm{F}_{2} \mathrm{C}-\mathrm{CFCl}\right]_{n}$, (PTFCE) and decomposing the polymer- $\mathrm{C}_{60}$ mix at high temperature to produce fluorine.

\section{Experimental}

The paramagnetic and ferromagnetic resonance measurements were made using a Varian E-9 spectrometer operating at $9.2 \mathrm{GHz}$ with $100 \mathrm{KHz}$ modulation. The temperature of the sample was controlled by flowing heated or cold nitrogen gas through a double-walled quartz tube, which is part of an ADP Heli-Tran system. This system is inserted through the center of the microwave cavity. The magnetization was obtained by measuring the magnetic field dependence of the ac susceptibility at $350 \mathrm{kHz}$ using a method similar to that described by Clover and Wolf [12]. The system consists of an HP 204C LC oscillator modified to have an external coil. The sample is contained in the coil, which is in a cryogenic dewar between the poles of a magnet. The change in the frequency of 
the oscillator, which is proportional to the change in susceptibility, is measured as a function of $\mathrm{dc}$ magnetic field strength using a HP 5314 frequency counter. The relative susceptibility as a function of $\mathrm{dc}$ magnetic field is measured by taking the difference in frequency between zero field and a given applied field. This method of measuring the susceptibility is quite sensitive but not widely used. Magnetic force microscope images were obtained using a Veeco Nano scope IV equipped with a magnetic tip. Raman measurements were made using a J. Y. Horiba confocal micro-Raman system employing a $25 \mathrm{~mW} \mathrm{He}-\mathrm{Ne}$ laser having a wavelength of $632.8 \mathrm{~nm}$ and focused to a spot of a 15-micron radius.

Crystalline $\mathrm{C}_{60}$, having $99.99 \%$ purity, was obtained from the Aldrich Chemical Company. Polytrifluorochloroethylene (PTFCE) was obtained from the Halocarbon Products Corporation. In this paper we will report clear evidence for ferromagnetism in a mixture of $\mathrm{C}_{60}$ and PTFCE subjected to heat treatment. In any report of ferromagnetism in an organic material, the purity of the starting materials is a critical issue, and we have paid considerable attention to sample analysis. It is particularly important to make sure no magnetic impurities are present in the starting materials. The starting $\mathrm{C}_{60}$ was analyzed by induction coil plasma mass spectrometry (ICPMS). The results indicated that signals from all metals were less than 1 part per billion (PPB). Electron paramagnetic resonance (EPR) of the $\mathrm{C}_{60}$ showed no evidence of the presence of magnetic elements or complexes. EPR is sensitive to 1 part in $10^{10}$. A very narrow line at $g=2.000$ was detected which has previously been identified as the $\mathrm{C}_{60}$ anion [13]. The PTFCE was also subjected to detailed analysis. Energy dispersive X-ray spectroscopy of PTFCE showed only the presence of carbon, fluorine, and chlorine, the constituents of the polymer. No other elements were detected. No magnetic species were detected by EPR. ICP-MS showed no magnetic metals above PPB in the PTFCE.

In a typical synthesis, 0.084 grams of PTFCE were dissolved in acetone and 0.040 grams of $\mathrm{C}_{60}$ added to the solution. The solution, while subjected to sonication, was allowed to slowly evaporate. The resulting residue was dried for some hours at $50^{\circ} \mathrm{C}$ to remove any entrapped acetone. The composite was heated to $160^{\circ} \mathrm{C}$ for two minutes and then rapidly quenched to room temperature.

\section{Results}

3.1. PTFCE as a Source of Fluorine. PTFCE was heated to $160^{\circ} \mathrm{C}$ for one hour and the Raman spectra recorded before and after the heating. No difference was observed between the frequencies of the Raman spectra indicating the material is not decomposing in the condensed phase.

However, the material sublimes at this temperature. In a second experiment the polymer was heated to $160^{\circ} \mathrm{C}$ for one hour in a small beaker which was on a hot plate. The beaker had a chilled slide on the top which enabled collection of the condensed vapor. The Raman spectra of the material condensed on the slide is shown at the bottom of Figure 1. On the top are the spectra in the same frequency region obtained from the polymer before heating. The two lines at

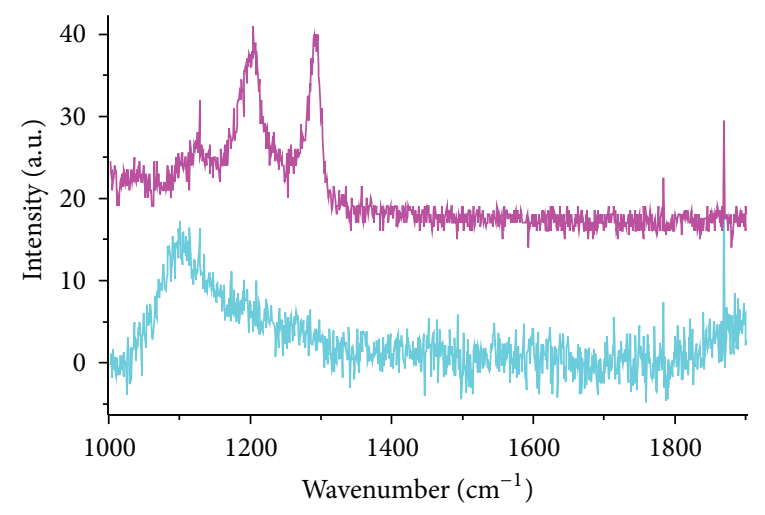

FIGURE 1: Raman spectra before decomposition of PTFCE showing the C-F vibrations at $1198 \mathrm{~cm}^{-1}$ and $1298 \mathrm{~cm}^{-1}$ and decomposed vapor of PTFCE condensed on a cold slide (bottom) after heating to $160^{\circ} \mathrm{C}$ showing absence of $\mathrm{C}-\mathrm{F}$ vibrations.

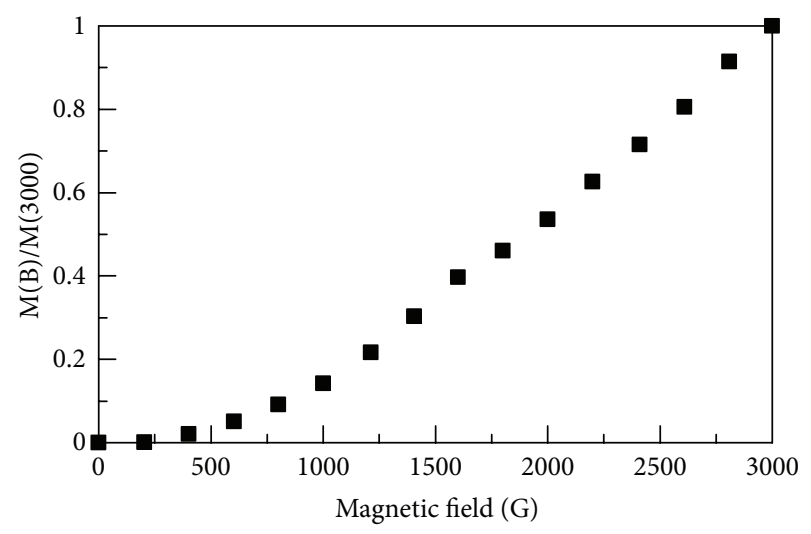

FIgURE 2: Magnetic field dependence of the ac susceptibility measured at $300 \mathrm{~K}$ and normalized to its value at 3000 Gauss.

$1198 \mathrm{~cm}^{-1}$ and $1298 \mathrm{~cm}^{-1}$, which are due to C-F vibrations, are completely gone in the spectra of the vapor indicating single fluorines are removed from the carbon atoms of the polymer in the vapor phase providing a source of atomic fluorine rather than diatomic fluorine.

3.2. Magnetization Measurements. Figure 2 is a plot of the ac susceptibility versus dc magnetic field at $300 \mathrm{~K}$ for the heattreated $\mathrm{C}_{60}$-TFPCE. The susceptibility has been normalized to the measured value at 3 Kilo Gauss. By comparing with a measurement on a sample of known magnetization, it is estimated the magnetization at 3000 Gauss is $0.07 \mathrm{emu} / \mathrm{gm}$. No field-dependent magnetization is observed in the separated starting materials subjected to the same treatment. Figure 3 shows the details at lower fields for increasing and decreasing dc magnetic field to and from 3000 Gauss showing a small hysteresis. Figure 4 presents the temperature dependence of the magnetization above room temperature measured in 


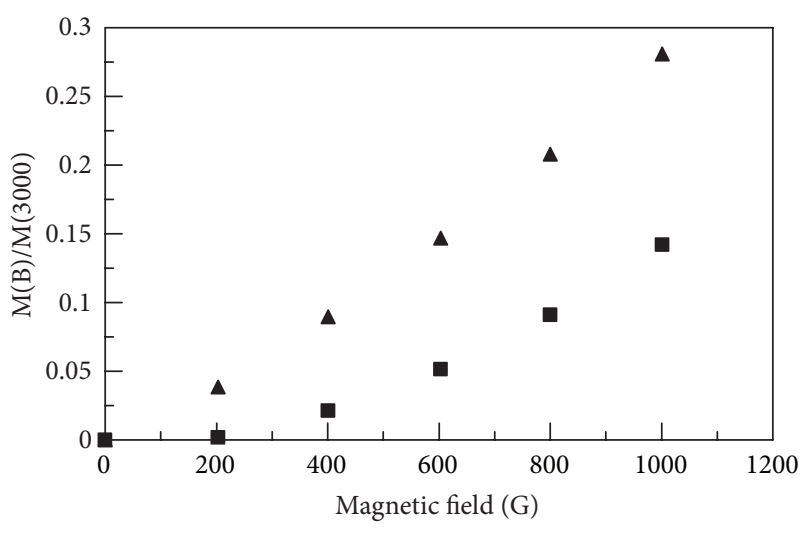

Figure 3: Magnetic field dependence of ac susceptibility at low fields for increasing and decreasing magnetic field to and from 3000 Gauss.

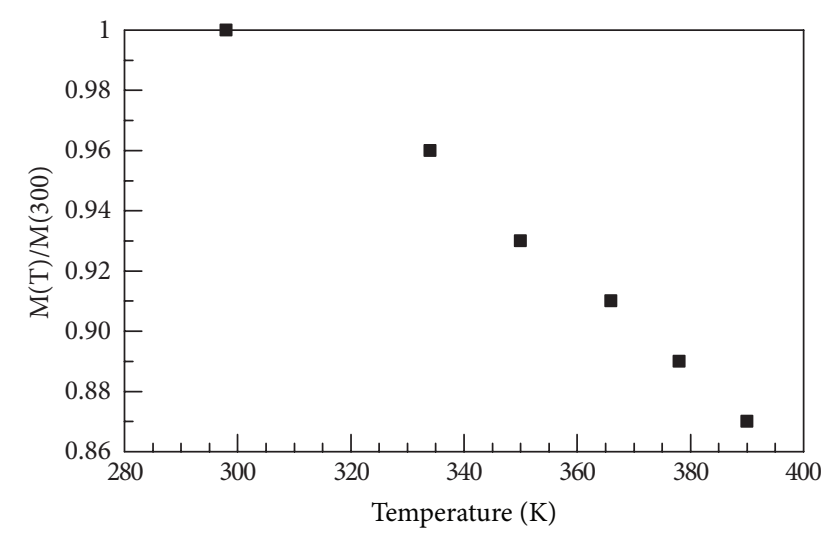

FIGURE 4: Temperature dependence of the magnetization above room temperature measured in a 3000-Gauss magnetic field and normalized to its value at $300 \mathrm{~K}$.

a 3000 Gauss field and normalized to its value at $300 \mathrm{~K}$. A fit of this data to the Bloch equation,

$$
M(T)=M s(0)\left[1-A T^{3 / 2}\right],
$$

yields a value of $A$ of $4.1246 \times 10^{-5}$. The temperature at which $M(T)$ is zero, the Curie temperature, is estimated to be $837 \mathrm{~K}$, from this fit. This is likely an overestimate because of deviations from the Bloch law near $T_{c}$ due to critical fluctuations. However, it is close to estimates of the Curie temperature obtained in $\mathrm{C}_{60}$ photolyzed in the presence of oxygen.

3.3. Magnetic Force Microscope Measurement. The PTFCE$\mathrm{C}_{60}$ material which was heat treated was pressed flat on a slide in order to have a smooth surface. Figure 5 shows a magnetic force microscope image of the material. The brighter regions indicate areas of ferromagnetism.

3.4. Ferromagnetic Resonance Measurements. The fluorinetreated material was heated above its melting point and a $4000 \mathrm{G}$ magnetic field applied. The material was then cooled

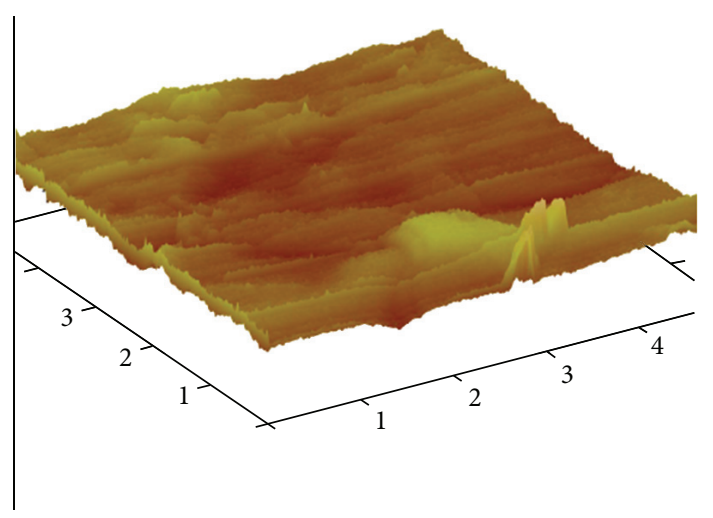

Figure 5: Magnetic Force microscope image of the flattened surface of the heated treated polymer containing $\mathrm{C}_{60}$. The units on the $x$ and $y$-axis are microns.

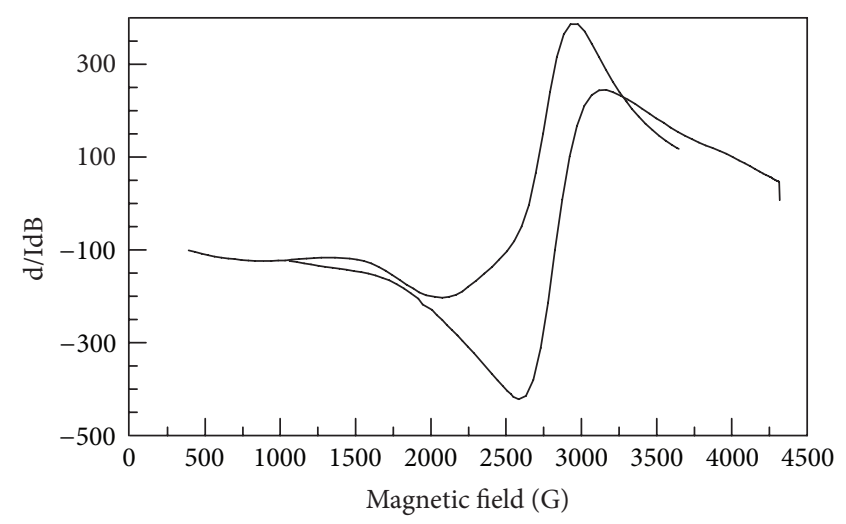

FIgURE 6: Ferromagnetic resonance spectra of the material melted and field cooled, as described in text, for the magnetic field parallel and perpendicular to the cooling field.

below the melting temperature in the magnetic field. This aligns and locks in the direction of maximum magnetization parallel to the direction of the applied magnetic field. Figure 6 shows the ferromagnetic resonance spectra for the sample oriented perpendicular and parallel to the direction of the cooling field. For a particle having axial symmetry, the dependence of the field position of the FMR signal is given by [14],

$$
H_{r}=H_{0}-H_{A}\left(\frac{1}{2}\right)\left(3 \cos ^{2} \theta-1\right),
$$

where $H_{A}=4 K / M$ is the anisotropy field, $K$ is the magnitude of the anisotropy constant, and $M$ is the magnetization. The angle, $\theta$, is between the direction of maximum magnetization and the applied dc field, $H_{r}$ is the magnetic field at the center of the FMR signal, and $H_{0}$ determines the $g$ value. Because $H_{r}$ is lower than the parallel orientation compared to the perpendicular orientation, it can be concluded that $K$ is positive. Fitting the data in Figure 6 to (2) allows determination of $H_{0}$ and $H_{A}$. The values for $H_{0}$ and $H_{A}$ are $2730 \mathrm{G}$ and $93 \mathrm{G}$, respectively, at $300 \mathrm{~K}$. The $g$ value is 2.287 . One of the characteristics of an FMR signal as opposed to an 


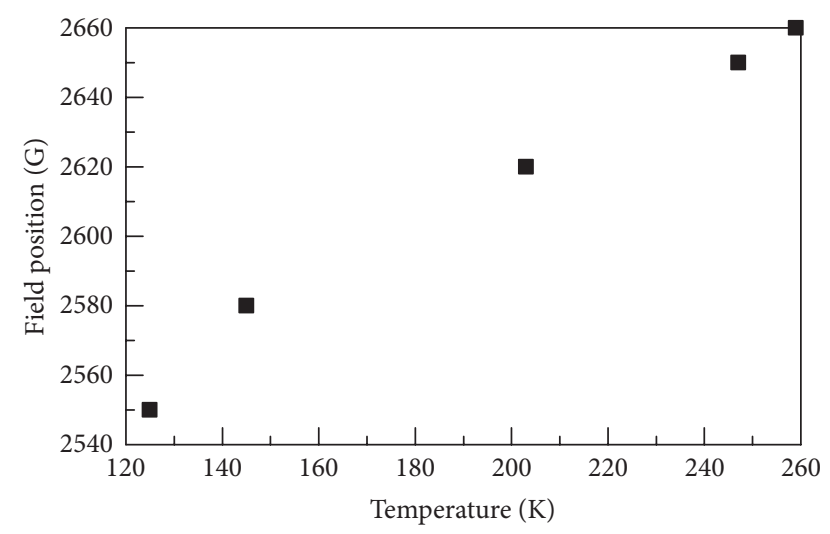

FIgURE 7: Temperature dependence of the field position of the FMR signal for the magnetic field perpendicular to the direction of the cooling field.

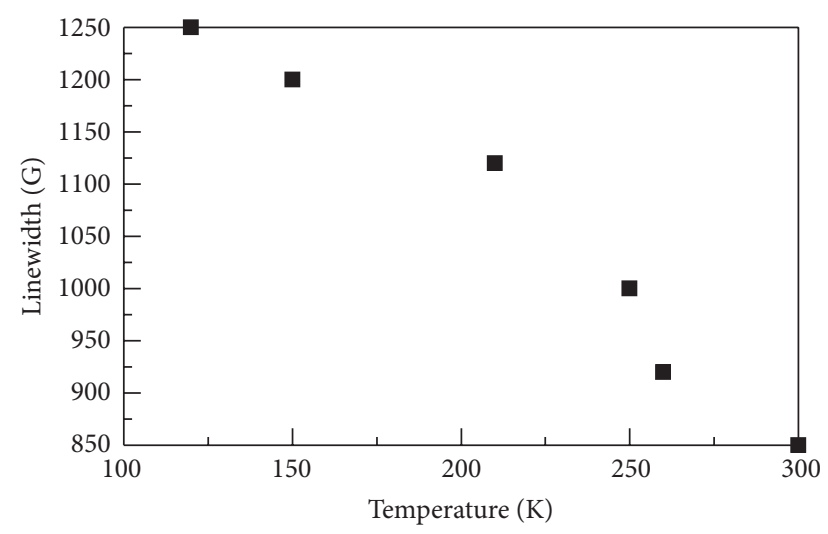

FIgURE 8: Temperature dependence of the line width of the FMR signal for the same orientation as in Figure 7.

EPR signal is a strong temperature dependence of the line width and field position of the resonance. Figure 7 is a plot of the temperature dependence of the field position for the sample oriented perpendicular to the direction of the cooling field showing a pronounced decrease in the field position with decreasing temperature. Figure 8 plots the line width as a function of decreasing temperature showing a marked broadening as the temperature is lowered. The data in Figures 7 and 8 confirm that the signal is an FMR signal.

\subsection{A Possible Model for the Origin of Ferromagnetism.} There has been a previous report of ferromagnetism in $\mathrm{C}_{60}$ subjected to a different fluorine treatment than that used here [15]. It was observed in $\mathrm{C}_{60}$ ultrasonically dispersed in dimethylformamide (DMF) solution of polyvinyl difluoride (PVDF), $\left[\mathrm{H}_{2} \mathrm{C}-\mathrm{CF}_{2}\right]_{n}$. However, the observed magnetism was not stable having a half-life of 30 hours at room temperature. Further the results were only reproducible 1 out of 15 times. In our observation the results are stable over years and reproducible once the correct synthesis conditions are determined. However, an interesting observation in the PVDF solution made material is that ionization time of flight mass spectrometry showed the formation of $\mathrm{C}_{60}$ oligomers having fluorine atoms bonded to each $\mathrm{C}_{60}$.

Previous density functional molecular orbital calculations of the minimum energy structure of the $\mathrm{F}-\mathrm{C}_{60}-\mathrm{C}_{60}-\mathrm{F}$ dimer indicated that the triplet state has a lower energy than the singlet state by $0.55 \mathrm{eV}[16,17]$. This suggests that the fluorinated dimer could be a possible source of the unpaired spin necessary to form a ferromagnetic state. However a calculation of the bond dissociation energy (BDE) to dissociate the dimer into $2\left(\mathrm{~F}-\mathrm{C}_{60}\right)$ indicates the dimer would not be stable above $400 \mathrm{~K}$ in disagreement with experimental observations.

As discussed in the introduction there have been a number of reports of ferromagnetism at lower temperatures in $\mathrm{C}_{60}$ subjected to heat treatment in the presence of $\mathrm{I}$, $\mathrm{IBr}$, and $\mathrm{H}$ [8-11]. X-ray diffraction measurements of these materials indicated the ferromagnetism was arising from a cubic phase of $\mathrm{C}_{60}$ where the $\mathrm{C}_{60}$ was functionalized with halogens or hydrogens. This is a likely possibility for the structure of the ferromagnetic phase of the fluorinated $\mathrm{C}_{60}$ observed here. A calculation of the $\mathrm{BDE}$ to remove $\mathrm{F}$ from $\mathrm{C}_{60}$ gives a value of $4.36 \mathrm{eV}$ indicating that $\mathrm{C}_{60}-\mathrm{F}$ is stable above $400 \mathrm{~K}$ further supporting this possibility [17].

There has been considerable work done on the fluorination of $\mathrm{C}_{60}$ which has been discussed in a number of reviews $[18,19]$. Generally the fluorination is achieved by exposing $\mathrm{C}_{60}$ to $\mathrm{F}_{2}$ gas at high temperature, which of course results in $\mathrm{C}_{60} \mathrm{~F}_{N}$ where $N$ is even. An even $N$ would have no net spin. The method of synthesis used here is likely exposing $\mathrm{C}_{60}$ to atomic fluorine produced by the removal of $\mathrm{F}$ from the TFPCE polymer. This would result in $N$ being odd giving the entity a net unpaired spin.

\section{Conclusion}

Field dependent ac susceptibility, ferromagnetic resonance, and magnetic force microscopy clearly show that exposing $\mathrm{C}_{60}$ to fluorine at high temperature produces a ferromagnetic phase having a Curie temperature well above room temperature. The results cannot be explained by the presence of magnetic impurities such as $\mathrm{Fe}, \mathrm{Ni}$, or Co or compounds of them because ICP-MS and EPR of the starting materials indicate that such materials are present at less than one part per billion. While the structure of the ferromagnetic phase is not determined, some possibilities can be considered. Dimers of $\mathrm{C}_{60}$ have been suggested to be the origin of the unpaired spin. DFT calculations of the $\mathrm{BDE}$ of $\mathrm{F}-\mathrm{C}_{60}=\mathrm{C}_{60}-\mathrm{F}$ indicate it unlikely to be stable above $400 \mathrm{~K}$. On the other hand $\mathrm{C}_{60}-\mathrm{F}$ is predicted to be stable at this temperature. This suggests the structure of the ferromagnetic phase may be cubic lattice of $\mathrm{C}_{60}-\mathrm{F}$, as observed for ferromagnetism in $\mathrm{C}_{60}-\mathrm{I}, \mathrm{C}_{60}-\mathrm{IBr}$, and $\mathrm{C}_{60}-\mathrm{H}$. However further work is needed to confirm this possibility.

\section{Conflict of Interests}

There is no conflict of interests. 


\section{References}

[1] P. M. Allemand, K. C. Khemani, A. Koch et al., "Organic molecular soft ferromagnetism in a fullerene $\mathrm{C}_{60}$, Science, vol. 253, no. 5017, pp. 301-303, 1991.

[2] T. L. Makaravoa et al., "Magnetic carbon," Nature, vol. 413, pp. 716-718, 2001.

[3] R. A. Wood, M. H. Lewis, M. R. Lees et al., "Ferromagnetic fullerene," Journal of Physics, vol. 14, article L385, 2002.

[4] T. L. Makarova, B. Sundqvist, and R. Höhne, "Retraction: magnetic carbon," Nature, vol. 440, article 707, 2006.

[5] P. Zhou, Z. H. Dung, A. M. Rao, and P. C. Eklund, "Reaction mechanism for the photopolymerization of solid fullerene $\mathrm{C}_{60}$," Chemical Physics Letters, vol. 211, pp. 337-340, 1993.

[6] Y. Murakami and H. Suematsu, "Magnetism of $\mathrm{C}_{60}$ induced by photo-assisted oxidation," Pure and Applied Chemistry, vol. 68, no. 7, pp. 1463-1467, 1996.

[7] F. J. Owens, Z. Iqbal, L. Belova, and K. V. Rao, "Evidence for high-temperature ferromagnetism in photolyzed $\mathrm{C}_{60}$ " Physical Review B, vol. 69, Article ID 033403, 4 pages, 2004.

[8] V. Buntar, H. W. Weber, and M. Ricco, "Magnetic irreversibility of $\mathrm{C}_{60}, \mathrm{C} 70$ and $\mathrm{I}_{-} \mathrm{C}_{60}$ fullerenes at low temperature: transition to a frozen magnetic glass state?" Solid State Communications, vol. 98, pp. 175-178, 1995.

[9] L. S. Grigoryan and M. Tokumoto, "New iodine containing polymers of $\mathrm{C}_{60}$ : synthesis, characterization and magnetic properties," Solid State Communications, vol. 96, pp. 523-528, 1995.

[10] H. Sekine, "Magnetic behavior and structure of the halogendoped fullerene $\mathrm{C}_{60}$," Journal of Applied Physics, vol. 72, no. 11, article 5448, 3 pages, 1992.

[11] M. Tokumoto, N. Kinoshita, Y. Tanaka et al., "Structure and magnetic properties of halogen-doped $\mathrm{C}_{60}$," Synthetic Metals, vol. 70, no. 1, pp. 1387-1388, 1995.

[12] R. B. Clover and W. P. Wolf, "Magnetic susceptibility measurements with a tunnel diode oscillator," Review of Scientific Instruments, vol. 41, no. 5, article 617, 5 pages, 1970.

[13] S. G. Kukolich and D. R. Huffman, "EPR spectra of $\mathrm{C}_{60}$ anion and cation radicals," Chemical Physics Letters, vol. 182, pp. 263-265, 1991.

[14] R. S. De Biasi and T. C. Devezas, "Anisotropy field of small magnetic particles as measured by resonance," Journal of Applied Physics, vol. 49, no. 4, pp. 2466-2469, 1978.

[15] M. Ata, M. Machida, H. Watanabe, and J. Seto, "Polymer- $\mathrm{C}_{60}$ composite with ferromagnetism," Japanese Journal of Applied Physics, vol. 33, pp. 1865-1871, 1994.

[16] O. E. Kvyatkovskii, I. B. Zakharova, A. L. Shelankov, and T. L. Makarova, "Spin-transfer mechanism of ferromagnetism in polymerized fullerenes: Ab initio calculations," Physical Review $B$, vol. 72, no. 21, Article ID 214426, 8 pages, 2005.

[17] M. Miller and F. J. Owens, "Stability of functionalized $C_{60}$ paramagnetic dimers and monomers," Chemical Physics, vol. 394, pp. 52-55, 2012.

[18] O. V. Boltalina, "Fluorination of fullerenes and their derivatives," Journal of Fluorine Chemistry, vol. 101, no. 2, pp. 273-278, 2000.

[19] R. Taylor, "Why fluorinate fullerenes?" Journal of Fluorine Chemistry, vol. 125, no. 3, pp. 359-368, 2004. 

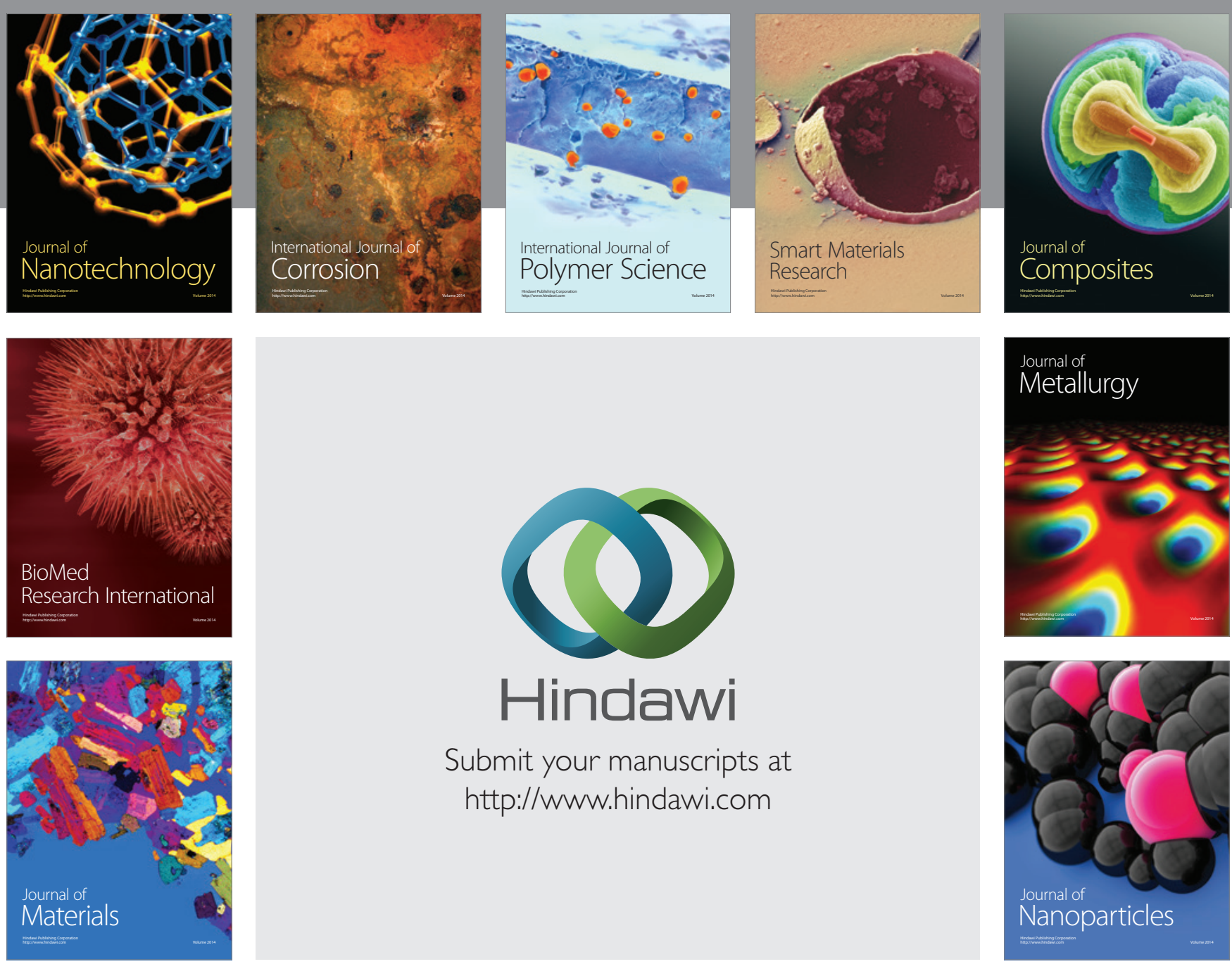

Submit your manuscripts at http://www.hindawi.com
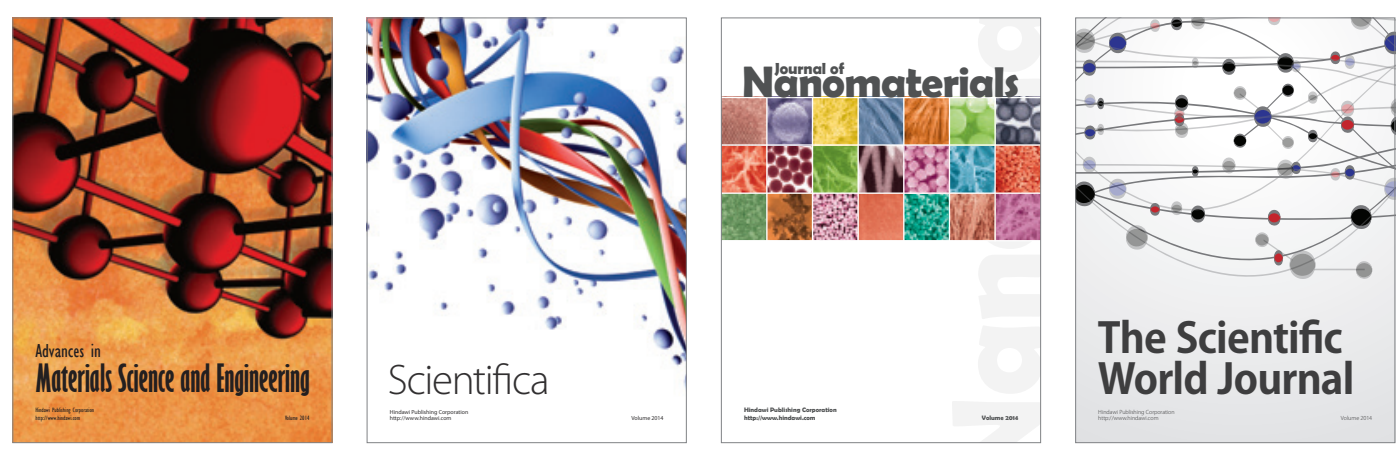

\section{The Scientific World Journal}
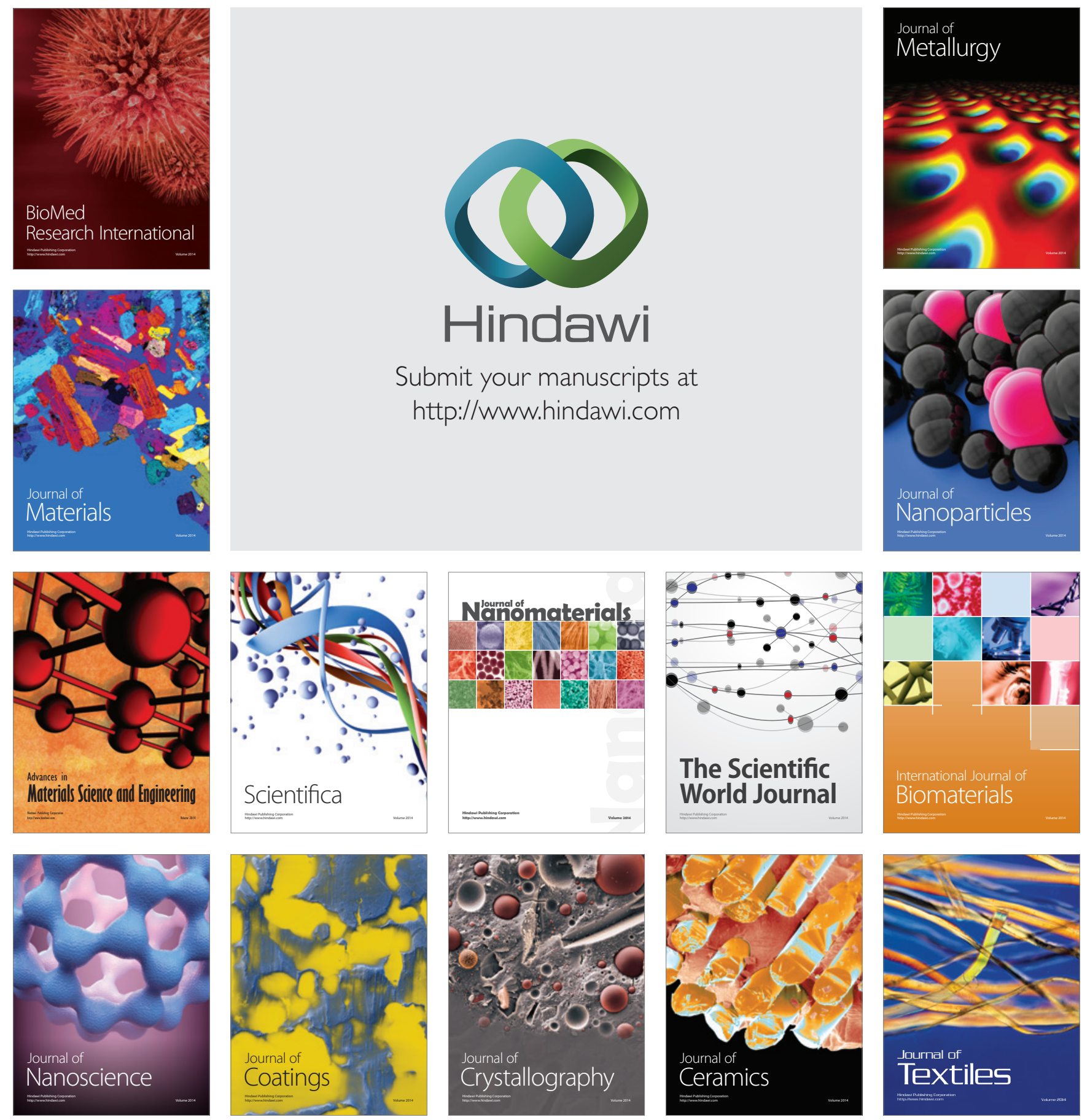